\title{
Elecciones Latinoamericanas. Selección y Cambio de voto
}

\author{
Richard Nadeau, Éric Bélanger, Michael S. Lewis-Beck, \\ Mathieu Turgeon, François Gélineau, María Celeste Ratto \\ Bruselas: Peter Lang. 2019. 266 páginas.
}

\section{Tomás Ciocci Pardo}

DOI: https://doi.org/10.46468/rsaap.14.1.R2

Una parte importante de la literatura que explica el comportamiento electoral distingue dos tipos de factores: los factores de largo plazo y los factores de corto plazo. Los primeros son estructurales y estables, como las características sociodemográficas de un ciudadano, su ideología y su identificación partidaria. Los segundos son menos estables, como la opinión sobre asuntos públicos generales o cuestiones más concretas como el desempeño de la economía. Dentro de esta línea de trabajos, conocidos como la Escuela de Michigan, se encuentra el libro de Nadeau et al. Los autores utilizan datos del Barómetro de las Américas (2008, 2010 y 2012) para analizar las principales relaciones causales dentro del "embudo de la causalidad" en 18 países de América Latina, con el objetivo de aportar al entendimiento de las elecciones en contextos de fragilidad democrática e institucional. ¿Qué es el embudo de causalidad? Un esquema de relaciones causales entre los determinantes del voto en donde la base del embudo son los factores de largo plazo, luego vienen los factores de corto plazo, y la punta del embudo representa el voto, siendo el clásico trabajo de Angus Campbell The American Voter (1960) el mayor de los exponentes de este tipo de abordajes.

¿Cómo votan los latinoamericanos?

Los autores reconocen que la literatura se ha dedicado al asunto, aunque la mayoría de los trabajos ponga el foco en factores o procesos específicos como el clientelismo, la calidad institucional, la corrupción o la economía. La carencia de una teoría integral del comportamiento electoral adaptada al contexto latinoamericano es el principal motivo de la investigación. Si bien América Latina tiene dos características distintivas como la extrema desigualdad y la diversidad étnico-lingüística, los autores no creen que los votantes latinoamericanos sean esencialmente diferentes de sus pares en democracias desarrolladas, por lo que intentan hacer viajar el "el embudo de la causalidad".

Esfuerzos anteriores, afirman los autores, arrojaron resultados satisfactorios en la aplicación del modelo de Michigan en otros contextos, como por ejemplo en Gran Bretaña, Francia o Irlanda, o incluso en regiones enteras como los países escandinavos. Su objetivo es aplicar el modelo de Michigan para entender las generalidades en todos los países de América Latina, y las diferencias entre los casos. El libro estudia el apoyo al partido de gobierno, a partir de la pregunta sobre a quién votaría en el encuestado "si la elección presidencial se celebrara mañana”, y considera cuatro grupos de factores: la estructura social (edad, genero, religión, región y raza/etnia), la clase y los bienes materiales (bienes materiales, educación, desempleo, propiedad y clientelismo), los anclajes políticos (identificación partidaria e ideológica) y los temas de interés 
(la intervención estatal, el autoritarismo, la corrupción, los derechos democráticos, el crimen y la economía). El último grupo representa los factores de corto plazo mientras que los tres anteriores los factores de largo plazo.

El primero de los resultados del libro indica que las características demográficas de los votantes explican muy poco sobre la selección del voto en general (teniendo en cuenta el ajuste de los modelos), aunque hay algunos efectos marcados. Los votantes mayores y blancos, las mujeres, los católicos y los asistentes a la iglesia tienden a votar en favor del candidato del partido y de gobierno si es de derecha (las mujeres en América Latina imitan la conducta de las mujeres del mundo desarrollado previo a la emancipación laboral y educativa). Los votantes blancos son más propensos a votar en favor de partidos de derecha que los votantes mestizos y mulatos, quienes por su parte son también más propensos a votar por un candidato de derecha que los negros o indígenas.

En segundo lugar, la estructura de clase (estatus de empleo y educación) y los bienes materiales (ingresos y la propiedad) tienen un efecto modesto sobre el voto. El factor clase está relacionado en buena parte a la emergencia política de gobiernos redistributivos, la cual ha sido capaz de politizar los temas de clase y movilizar el apoyo de los desempleados y de los pobres, aunque no se encuentra un efecto consistente del clientelismo.

El tercer resultado marca una clara predominancia de las variables de anclaje por sobre los dos conjuntos de variables anteriores. El efecto de la identificación partidaria, por su parte, es más fuerte y sistemático en la selección del voto, en comparación con la ideo- logía (la única excepción es Chile, en donde el factor posicionamiento ideológico explica mucho de la variación en el voto). Aun así, el efecto de la variable identificación partidaria es más bajo en esta región que en las democracias desarrolladas. Por último, la economía nacional, el crimen, la corrupción y la democracia, tienen un impacto más fuerte como temas de interés que la intervención estatal en la economía y el autoritarismo. Los temas importan y mucho en América Latina, siendo fundamental su inclusión para mejorar las medidas de ajuste de los modelos estadísticos.

En términos más generales, el poder explicativo del modelo Michigan para los países de América Latina es similar a lo que ha sido observado en las democracias emergentes de Europa Oriental, pero más bajo que en las democracias desarrolladas. Esto se debe al débil efecto (en comparación con estas últimas) de las variables sociopsicológicas, tales como la identificación partidaria e ideológica, factores vinculados a los años de historia democrática faltos de desarrollo en la región.

El libro aporta tres conclusiones importantes. La primera de ellas es que el modelo de Michigan puede viajar. La principal diferencia en su aplicación respecto de los países desarrollados tiene que ver con factores que van madurando y se van afianzando con los años de democracia continuada. Teniendo en cuenta esto, podría esperarse una mayor convergencia para el futuro, a partir de un aumento del vínculo entre etiquetas partidarias y votantes, como así también de un ordenamiento ideológico más estable en las elites y votantes.

Segundo, se muestra la especificidad de América Latina en relación con el modelo de Michigan. Los factores 
explicativos del voto pueden variar en fuerza de un país o un continente a otro. Vemos que, dentro de este marco teórico, el comportamiento electoral de Latinoamérica tiene sus propias fortalezas, incluyendo la importancia de la raza/etnia y la religión sobre la selección del voto, la mayor relevancia de la identificación partidaria en comparación con la ideología, y la prominencia de temas de interés tales como la corrupción, la economía y el respeto por los derechos democráticos.

Tercero, se muestra la especificidad de ciertos grupos en función de las características de los países. El efecto de la raza/etnia es más pronunciado en aquellos países con mayor proporción de población negra o indígena, la conexión entre la riqueza y apoyo a la derecha es más fuerte en países que han implementado políticas redistributivas, y el efecto de la identificación partidaria es más débil en países con sistemas de partidos más fragmentados.

El libro resulta de vital importancia para la literatura. En primer lugar, porque combina un fuerte encuadre teórico aplicado en democracias desarrolladas con diseños estadísticos que contemplan el contexto de aplicación de esos modelos. En segundo lugar, porque utiliza datos sistematizados a escala regional y con significancia estadística nacional, lo que permite no solo ver la aplicación del embudo de la causalidad sino también la variación de su aplicación. Por último, porque muestra cómo, en un contexto de fragilidad institucional, las teorías generadas en países desarrollados funcionan de una forma aceptable. Esto indica que el votante latino tiene un comportamiento parecido al de sus pares en democracias desarrolladas, dependiendo las diferencias del tiempo y la maduración de los sistemas políticos. El libro es un ejemplar único en su intento por aportar evidencia explicativa de los determinantes del voto en América Latina, siendo fundamental su lectura en cursos de grado y posgrado sobre opinión pública y comportamiento electoral en la región. 